Article

\title{
Effect of Metal Oxide-Support Interactions on Ethylene Oligomerization over Nickel Oxide/Silica-Alumina Catalysts
}

\author{
Ji Sun Yoon ${ }^{1,+}$, Min Bum Park ${ }^{2,+}$, Youngmin Kim ${ }^{1} \mathbb{D}$, Dong Won Hwang ${ }^{1,3}$ and \\ Ho-Jeong Chae ${ }^{1,3, *}$ \\ 1 Carbon Resources Institute, Korea Research Institute of Chemical Technology, Daejeon 34114, Korea; \\ jsy523@krict.re.kr (J.S.Y.); ykim@krict.re.kr (Y.K.); dwhwang@krict.re.kr (D.W.H.) \\ 2 Department of Energy and Chemical Engineering, Incheon National University, Incheon 22012, Korea; \\ mbpark@inu.ac.kr \\ 3 Department of Green Chemistry \& Biotechnology, University of Science and Technology, \\ Daejeon 34113, Korea \\ * Correspondence: hjchae@krict.re.kr; Tel.: +82-42-860-7290 \\ + These authors contributed equally.
}

Received: 25 October 2019; Accepted: 7 November 2019; Published: 8 November 2019

\begin{abstract}
We investigated the interactions between nickel oxide and silica-alumina supports, which were applied to the catalytic oligomerization of ethylene by powder X-ray diffraction, UV diffuse reflectance spectroscopy, $\mathrm{H}_{2}$ temperature-programmed reduction, and $\mathrm{X}$-ray photoelectron spectroscopy. The catalytic activity was also correlated with the acidity of catalysts determined by $\mathrm{NH}_{3}$ temperature-programmed desorption and pyridine FT-IR spectroscopy. Although all the catalysts had similar Ni contents, their catalytic performances were strongly influenced by the strength of the metal oxide-support interaction. Strong interaction promoted the formation of nickel aluminate on the catalyst surface, and resulted in low catalytic activity due to reducing the amount of nickel oxide active sites. However, weak interaction favored the aggregation of nickel oxide species into larger particles, and thus resulted in low ethylene conversion and selectivity to oligomers. Eventually, the optimal activity was realized at the medium interaction strength, preserving a high amount of both active nickel oxides and acid sites.
\end{abstract}

Keywords: ethylene; oligomerization; nickel oxide; silica-alumina; metal oxide-support interaction

\section{Introduction}

Biofuels and biochemicals have a great deal of interest because of global warming. Among them, bioethanol is one of the most abundant sustainable raw materials of biocarbon sources today [1]. Bioethanol-derived ethylene could be widely used in the syntheses of transportation fuels, chemicals, polymer derivatives, etc. [1-3]. In particular, the oligomerization of bioethanol-derived ethylene over heterogeneous catalysts has been extensively investigated as part of green chemistry processes [4-6]. Even though heterogeneous catalysis afford low product yields due to suffering from mass transfer limitations, they do not feature the inherent drawbacks of homogeneous catalysis, such as difficulty in handling and separation from products, poor result reproducibility, and high cost, and thus being a subject of intensive research.

The heterogeneous oligomerization of ethylene has usually been attempted using Ni-based solid acid catalysts supported on several zeolites such as ZSM-5 [7-10], Y [11-14], beta [15], MCM-22 [13,16,17], and MCM-36 [16,17], and ordered mesoporous Al-SBA-15 [18,19], Al-MCM-48, and Al-MCM-41 [13,18,20-24]. In addition, various non-crystalline amorphous materials, i.e., silica-alumina (SA) [25-30], 
sulfated alumina [31-34], $\mathrm{B}_{2} \mathrm{O}_{3}-\mathrm{Al}_{2} \mathrm{O}_{3}$ [35], $\mathrm{ZrO}_{2} / \mathrm{WO}_{3}$ [36,37], $\mathrm{ZrO}_{2} / \mathrm{MoO}_{3}$ [38], $\mathrm{ZrO}_{2} / \mathrm{SO}_{4}{ }^{2-}$ [39], and $\mathrm{TiO}_{2} / \mathrm{SO}_{4}{ }^{2-}$ [40], have been studied as a support for the ethylene oligomerization. Since both Brønsted (B.A) and Lewis acid (L.A) sites are also crucial for ethylene oligomerization, numerous reports have demonstrated the dependence of catalytic activity on the acidity of support materials (reflected by the $\mathrm{Si} / \mathrm{Al}$ ratio in case of SAs) and the nature and content of transition metals $[7,18,25,28,29,36,37,41,42]$.

The interaction between metal oxide and support has been demonstrated in a redox process as a representative phenomenon using an iron or vanadium oxide supported on silica, zirconia, alumina, ceria, niobia, titania, etc. via Møssbauer, Raman, IR, and temperature-programmed reduction (TPR) [43-45]. Moreover, metal oxide-support interaction or surface oxide-support interaction has been reported to exhibit a pattern similar to metal-support interaction $[43,45]$. The metal-support interaction has been well established theoretically in various catalytic reactions such as the water-gas shift reaction [46], hydrogenation [47], and Fischer-Tropsch synthesis [48], and specifically divided into three types according to interaction strength, i.e., strong (SMSI), medium (MMSI), and weak metal-support interaction (WMSI). These usually depend on the loaded metal amount, calcination conditions, and surface species of support, including additives [49]. For example, SMSI can be explained from three representative viewpoints. The first explanation assumes that support ions such as $\mathrm{Ti}^{4+}$ are partially reduced by hydrogen spillover in adjacent metal particles, which causes the formation of species such as $\mathrm{Ti}_{4} \mathrm{O}_{7}$ [50]. According to the second explanation, SMSI changes the shape of supported metal particles to promote their dispersion [50], whereas the third explanation suggests that the reduced titanium oxide represented as $\mathrm{TiOx}$ migrates to surfaces of metal such as $\mathrm{Pt}$, $\mathrm{Rh}$, or Ni [51,52].

Herein, we performed ethylene oligomerization over heterogeneous catalysts comprising nickel oxide supported on $\mathrm{SAs}(\mathrm{NiOx} / \mathrm{SA})$ with different $\mathrm{Si} / \mathrm{Al}$ ratios to produce fuel grade hydrocarbons. In our previous study, the Ni/Siral-30 with $4 \mathrm{wt} \%$ of Ni (NiOx/SA-028 in this study, see below) had showed a good catalytic activity for ethylene oligomerization in a continuous fixed-bed reactor [53]. This catalyst gave almost complete ethylene conversion and stability over $100 \mathrm{~h}$ at $200^{\circ} \mathrm{C}, 10 \mathrm{bar}$, and a weight hourly space velocity (WHSV) of $0.375 \mathrm{~h}^{-1}$. In a series of previous research, in this study, we investigated the effects of support acidity, $\mathrm{Ni}$ oxidation state, and particle size of $\mathrm{Ni}$-containing species, and thus the metal oxide-support interaction on the catalytic reaction. To the best of our knowledge, this is the first study of the metal oxide-support interaction for the ethylene oligomerization. Similar to the metal-support interaction, the strength of the metal oxide-support interaction was classified with three stages of strong, medium, and weak. The electronic properties and acidity of catalysts were determined by UV diffuse reflectance spectroscopy (UV-DRS), $\mathrm{H}_{2}$-TPR, X-ray photoelectron spectroscopy (XPS), $\mathrm{NH}_{3}$-temperature programmed desorption $\left(\mathrm{NH}_{3}\right.$-TPD), and pyridine-FT-IR ( $p y$-FT-IR).

\section{Results and Discussion}

\subsection{Structural and Electronic Properties of NiOx/SA Catalysts}

The chemical composition and textural properties of the catalysts prepared in this study are summarized in Table 1. Five NiOx/SA catalysts with different $\mathrm{Si} / \mathrm{Al}$ ratios but nearly identical Ni contents (3.4-3.9 $\mathrm{wt} \%$ ) were synthesized by an incipient wetness impregnation method. The prepared catalysts were designated as NiOx/SA-001, -007, - $028,-047$, and -386 , respectively, according to their $\mathrm{Si} / \mathrm{Al}$ ratios. The textural properties did not show any trends according to the $\mathrm{Si} / \mathrm{Al}$ ratios. Although the activity and stability of oligomerization are most affected by mass transfer (diffusion), the large pore sizes in several nanometers of these $\mathrm{NiOx} / \mathrm{SA}$ catalysts may have no diffusion limitation problem. 
Table 1. Chemical composition and textural properties of the catalysts prepared in this study.

\begin{tabular}{|c|c|c|c|c|c|c|c|}
\hline \multirow{2}{*}{ Catalyst } & \multirow{2}{*}{$\mathrm{Si} / \mathrm{Al}^{1}$} & \multirow{2}{*}{$\begin{array}{l}\text { Ni Content } \\
(\text { wt \% })^{1}\end{array}$} & \multicolumn{3}{|c|}{ BET Surface Area $\left(\mathrm{m}^{2} / \mathrm{g}\right)^{2}$} & \multirow{2}{*}{$\begin{array}{l}\text { Pore Volume } \\
\left(\mathrm{cm}^{3} / \mathrm{g}\right)^{4}\end{array}$} & \multirow{2}{*}{$\begin{array}{l}\text { Pore Size } \\
(\mathrm{nm})^{4}\end{array}$} \\
\hline & & & Total & Microporous & External $^{3}$ & & \\
\hline NiOx/SA-001 & 0.01 & 3.81 & 145 & 19 & 126 & 0.4 & 13.0 \\
\hline NiOx/SA-007 & 0.07 & 3.41 & 324 & 21 & 303 & 0.7 & 6.0 \\
\hline $\mathrm{NiOx} / \mathrm{SA}-028$ & 0.28 & 3.94 & 321 & 87 & 234 & 0.7 & 8.0 \\
\hline $\mathrm{NiOx} / \mathrm{SA}-047$ & 0.47 & 3.85 & 449 & 23 & 426 & 1.2 & 7.7 \\
\hline NiOx/SA-386 & 3.86 & 3.80 & 484 & 0 & 484 & 0.7 & 4.9 \\
\hline
\end{tabular}

${ }^{1}$ Determined by elemental analysis. ${ }^{2}$ Calculated from $\mathrm{N}_{2}$ sorption data. ${ }^{3}$ Determined according to the $t$-plot method. ${ }^{4}$ Calculated using BJH formalism from the $\mathrm{N}_{2}$ desorption branch isotherm.

Figure 1 shows their powder XRD patterns. For comparison, some reference patterns of the Inorganic Crystal Structure Database (ICSD) are also given in Figure 1. All the NiOx/SA catalysts featured the presence of spinel and trigonal alumina phases described by Fm $3 m$ (ICSD \#30267) and $\mathrm{R} \overline{\mathrm{C}} \mathrm{CH}$ (ICSD \#30025) space groups, respectively. In addition, trigonal and monoclinic nickel oxides phases represented by $\mathrm{Fm} 3 \mathrm{~m}$ (NiO; ICSD \#24018) and C12/m1 $\left(\mathrm{NiO}_{2} ; \mathrm{ICSD} \# 88720\right)$ space groups were also detected. The increasing alumina content upon going from NiOx/SA-386 to NiOx/SA-001 favored a spinel structure, whereas the trigonal structure was dominant in the catalysts with low alumina content. Since the nickel oxide phase contained both $\mathrm{NiO}$ and $\mathrm{NiO}_{2}$ phases, we suggested the non-stoichiometric nickel oxide as the nickel oxide phase (NiOx). This can also be confirmed by $\mathrm{H}_{2}$-TPR and $\mathrm{Ni} 2 \mathrm{p}$ of XPS spectra (see below). $\mathrm{NiO}_{2}$ was the only nickel oxide species observed together with $\mathrm{NiO}$, but other species such as $\mathrm{Ni}_{2} \mathrm{O}_{3}$ were absent.

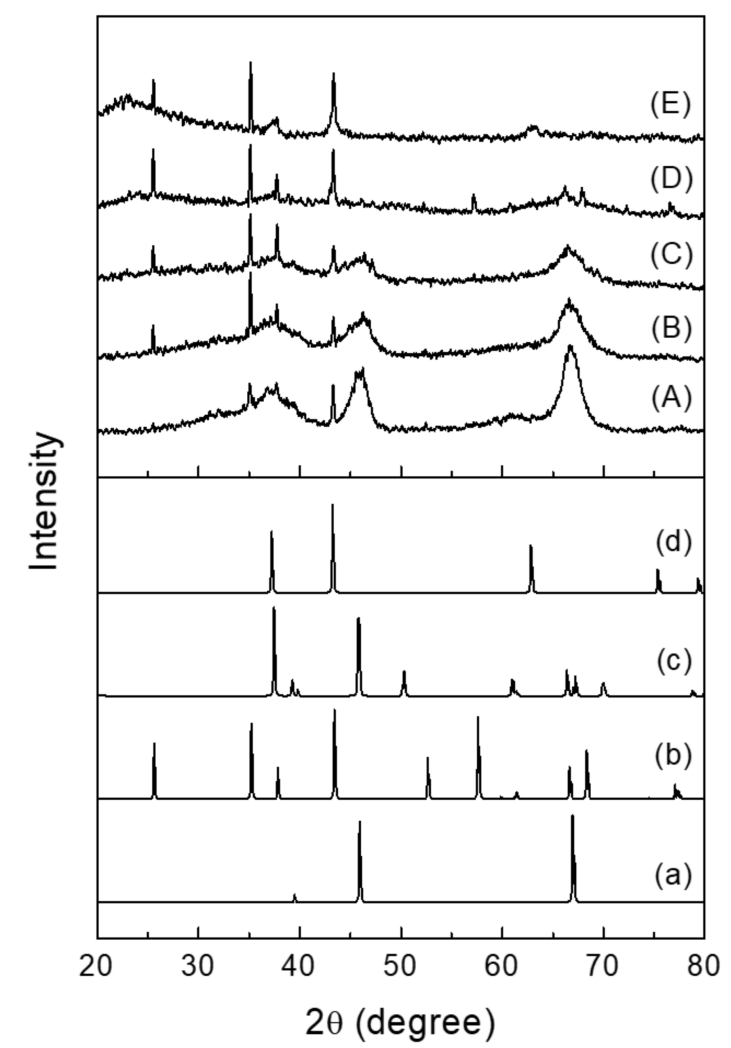

Figure 1. XRD patterns of (A) NiOx/SA-001, (B) NiOx/SA-007, (C) NiOx/SA-028, (D) NiOx/SA-047, and (E) NiOx/SA-386. Inorganic Crystal Structure Database (ICSD) reference patterns of (a) $\mathrm{Al}_{2} \mathrm{O}_{3}$ (\#30267, $\mathrm{F} \overline{\mathrm{m}} 3 \mathrm{~m}),(\mathrm{b}) \mathrm{Al}_{2} \mathrm{O}_{3}$ (\#30025, $\left.\mathrm{R} \overline{\mathrm{C}} \mathrm{H}\right),(\mathrm{c}) \mathrm{NiO}_{2}$ (\#88720, C12/m1), and (d) $\mathrm{NiO}(\# 24018, \mathrm{~F} \mathrm{~m} 3 \mathrm{~m})$.

It is well known that $\mathrm{Ni}^{2+}$ can migrate into the alumina lattice by solid-state diffusion during impregnation when the alumina surface is dissolved in $\mathrm{Ni}\left(\mathrm{NO}_{3}\right)_{2}$ solution and calcination is carried out above $550^{\circ} \mathrm{C}[49,54,55]$. For example, $\gamma$-alumina is well known to have a cation-deficient spinel 
structure featuring mixed tetrahedral and octahedral sites that can accommodate divalent metal cations such as $\mathrm{Ni}^{2+}$ to achieve structural stabilization [49,55]. However, in this study, even though some $\mathrm{Ni}$ ions were accommodated in the alumina lattice, no bulk $\mathrm{NiAl}_{2} \mathrm{O}_{4}$ phase was observed in the XRD pattern, which was probably due to the small Ni loading (3.4-3.9 wt \%) and the well-dispersed amorphous structure of the support surface (Figure 1). In addition, only small particles of NiOx well dispersed on SAs were observed especially in NiOx/SA-001, -007, and -028, while NiOx/SA-047 and -386 exhibited aggregated $\mathrm{NiOx}$ particles in specific regions of supports, as revealed by high-angle-annular dark-field (HAADF)-transmission electron microscope (TEM) images and energy-dispersive $X$-ray (EDS) elemental maps (Figure S1).

The symmetry and coordination of catalyst surface species were investigated by UV-DRS (Figure 2). According to the literature, the reflectance spectra of $\mathrm{NiO}$ and $\mathrm{NiAl}_{2} \mathrm{O}_{4}$ exhibited distinct bands ascribed to different $d-d$ transitions. Specifically, the bands at 377 and $715 \mathrm{~nm}$ were assigned to octahedral $\mathrm{Ni}^{2+}$ in the NiO lattice, with the ${ }^{3} \mathrm{~A}_{2 \mathrm{~g}} \rightarrow{ }^{3} \mathrm{~T}_{1 \mathrm{~g}}$ (F) transition being a fingerprint of $\mathrm{NiO}$ [49,56-58]. In addition, the band at $510 \mathrm{~nm}$ was ascribed to charge transfer in $\mathrm{NiO}$ [57]. $\mathrm{NiO}$ in $\mathrm{Al}_{2} \mathrm{O}_{3}$ exhibited significantly different absorption bands at 555 and 600-645 nm (doublet), which were attributed to ${ }^{3} \mathrm{~T}_{1} \rightarrow{ }^{1} \mathrm{~T}_{2}$ and ${ }^{3} \mathrm{~T}_{1} \rightarrow{ }^{3} \mathrm{~T}_{1}(\mathrm{P})$ transitions of tetrahedrally coordinated $\mathrm{Ni}^{2+}$ in the $\mathrm{Al}_{2} \mathrm{O}_{3}$ lattice, respectively, with the band at 416-430 nm ascribed to the ${ }^{3} \mathrm{~A}_{2 \mathrm{~g}} \rightarrow{ }^{3} \mathrm{~T}_{1 \mathrm{~g}}(\mathrm{P})$ transition of octahedrally coordinated $\mathrm{Ni}^{2+}$ in the $\mathrm{Al}_{2} \mathrm{O}_{3}$ lattice $[49,56-58]$. Thus, $\mathrm{Ni}^{2+}$ ions were accommodated in both octahedral and tetrahedral sites of the $\mathrm{Al}_{2} \mathrm{O}_{3}$ oxygen lattice, which led to nickel aluminate as a surface spinel phase [58]. Furthermore, $\mathrm{NiO}$ bands at 377 and $715 \mathrm{~nm}$ observed in NiOx/SA-386 and that at $715 \mathrm{~nm}$ observed in NiOx/SA-047 were in agreement with the results of EDS mapping and HAADF-TEM imaging, which revealed that $\mathrm{NiOx} / \mathrm{SA}-386$ featured aggregated $\mathrm{NiO}$ particles on the SA surface (Figure S1).

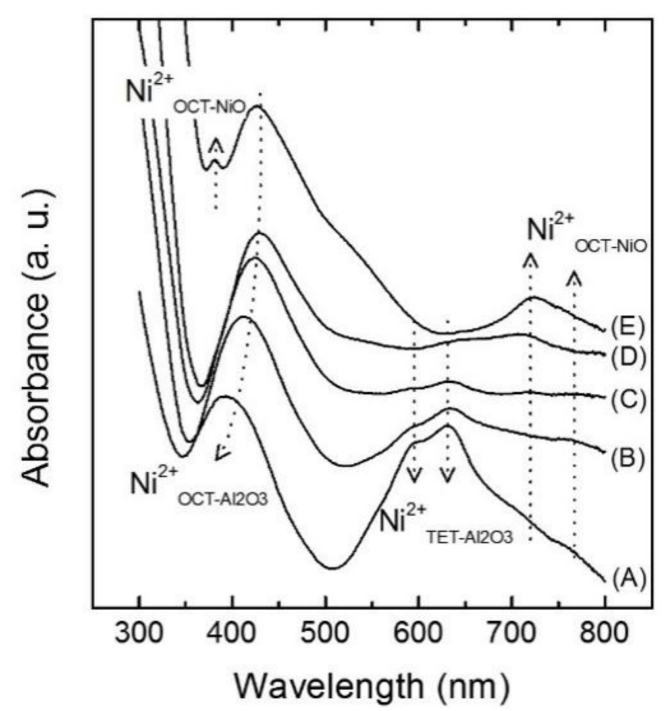

Figure 2. UV-DRS spectra of (A) NiOx/SA-001, (B) NiOx/SA-007, (C) NiOx/SA-028, (D) NiOx/SA-047, and (E) NiOx/SA-386.

$\mathrm{H}_{2}$-TPR profiles were obtained to investigate the correlation between the reducibility from NiOx-SA support interaction and activity (Figure 3 and Table 2). Any distinct peaks were not detected from bare SA-007, while Ni-loaded SA catalysts showed several reduction peaks, especially in $\mathrm{NiOx} / \mathrm{SA}-386$. The observed peaks were assigned to the reduction of $\mathrm{Ni}_{2} \mathrm{O}_{3}$ [59], allowing the reduction of $\mathrm{Ni}^{\delta+}$ species to be classified into three steps based on the XRD pattern of NiOx/SA-386: (i) NiOx $(1<\mathrm{x} \leq 2)$ to $\mathrm{NiO}$ at $\sim 391{ }^{\circ} \mathrm{C}$; (ii) the fragmentation of large $\mathrm{NiO}$ particles into smaller ones at $\sim 544^{\circ} \mathrm{C}$; and (iii) a reduction of small $\mathrm{NiO}$ particles to $\mathrm{Ni}$ at $\sim 623^{\circ} \mathrm{C}$. However, except for NiOx/SA-386, the other Al-rich $\mathrm{NiOx} / \mathrm{SA}$ catalysts only exhibited a broad $\mathrm{NiO}$ reduction peak that appeared around $700-850{ }^{\circ} \mathrm{C}$, which was shifted to higher temperature with increasing alumina fraction [60-63]. The peak above $800^{\circ} \mathrm{C}$ was attributed to the reduction of the least reactive $\mathrm{Ni}^{2+}$ species in the surface spinel structure 
of $\mathrm{NiAl}_{2} \mathrm{O}_{4}$, i.e., nickel ions coordinated in octahedral and tetrahedral sites of alumina and strongly interacting with the support $[56,58,59,64]$. The formation of surface $\mathrm{NiAl}_{2} \mathrm{O}_{4}$ by nickel ion incorporation accounted for the high dispersion of $\mathrm{NiO}$ particles [65].

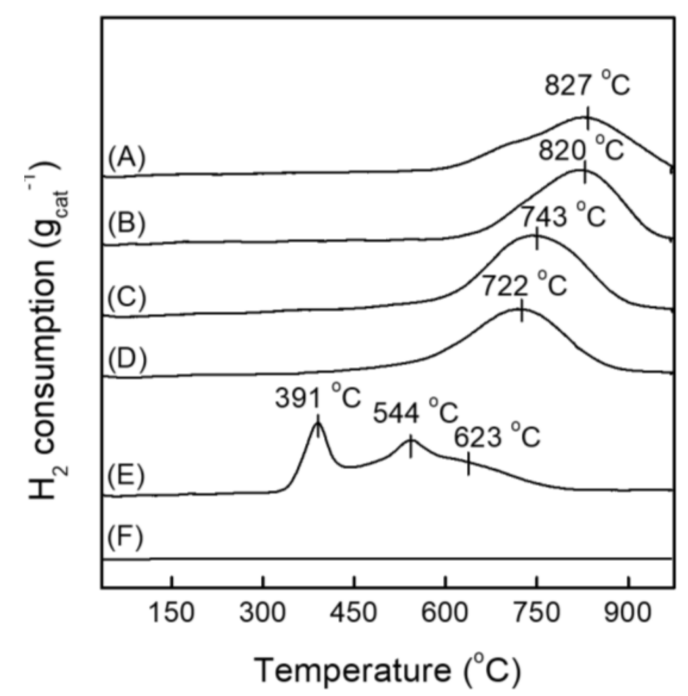

Figure 3. $\mathrm{H}_{2}$-TPR profiles of (A) NiOx/SA-001, (B) NiOx/SA-007, (C) NiOx/SA-028, (D) NiOx/SA-047, (E) NiOx/SA-386, and (F) SA-007.

Table 2. The amount of reducible Ni species determined by $\mathrm{H}_{2}-\mathrm{TPR}$.

\begin{tabular}{|c|c|c|c|c|}
\hline \multirow{2}{*}{ Catalyst } & \multirow{2}{*}{$\begin{array}{l}\text { Total } \mathrm{H}_{2} \text { Uptake } \\
(\mathrm{mmol} / \mathrm{g})\end{array}$} & \multicolumn{3}{|c|}{ Reducible Ni Species (mmol/g) ${ }^{1}$} \\
\hline & & $\mathrm{NiOx} \rightarrow \mathrm{NiO}_{\mathrm{L}}{ }^{2}$ & $\mathrm{NiO}_{\mathrm{L}}{ }^{2} \rightarrow \mathrm{NiO}_{\mathrm{S}}{ }^{3}$ & $\mathrm{NiO}_{\mathrm{S}}{ }^{3} \rightarrow \mathrm{Ni}$ \\
\hline $\mathrm{NiOx} / \mathrm{SA}-001$ & 1.47 & - & - & $1.47(827)$ \\
\hline $\mathrm{NiOx} / \mathrm{SA}-007$ & 1.88 & - & - & $1.88(820)$ \\
\hline $\mathrm{NiOx} / \mathrm{SA}-028$ & 2.46 & - & - & $2.46(743)$ \\
\hline $\mathrm{NiOx} / \mathrm{SA}-047$ & 2.21 & - & - & $2.21(722)$ \\
\hline $\mathrm{NiOx} / \mathrm{SA}-386$ & 2.42 & $0.75(391)$ & $1.03(544)$ & $0.64(623)$ \\
\hline
\end{tabular}

${ }^{1}$ The value given in parentheses is the temperature $\left({ }^{\circ} \mathrm{C}\right)$ centered at the highest reduction peak. ${ }^{2} \mathrm{NiO}_{\mathrm{L}}$ indicates aggregated particles of $\mathrm{NiO} .{ }^{3} \mathrm{NiO}_{\mathrm{S}}$ indicates well-dispersed particles of $\mathrm{NiO}$.

Reduction patterns of $\mathrm{NiOx}$ on different SAs depended on the strength of $\mathrm{NiOx}-\mathrm{SA}$ interactions, being influenced by the alumina content and phase. The $\mathrm{H}_{2}$-TPR profile of NiOx/SA-386 showed three main peaks, corresponding to (in the order of increasing temperature) the reduction of large (bulk-like) $\mathrm{NiO}$ particles, the reduction of $\mathrm{NiO}$ weakly interacting with alumina (Al-O-Ni moieties), and the reduction of $\mathrm{Ni}$ species incorporated into alumina (crystalline $\mathrm{NiAl}_{2} \mathrm{O}_{4}$ ) [66-69]. Thus, the reduction peak shifted to lower temperatures with the decreasing strength of the $\mathrm{NiOx}$-support interaction. Based on the obtained $\mathrm{H}_{2}$-TPR profiles, the above interaction was the strongest for NiOx/SA-001 and $\mathrm{NiOx} / \mathrm{SA}-007$, resulting in the formation of surface $\mathrm{NiAl}_{2} \mathrm{O}_{4}$ species and highly dispersed small and poorly reducible $\mathrm{NiO}$ particles $[49,70]$. On the other hand, NiOx/SA-386 exhibited a weak metal oxide-support interaction leading to the formation of larger $\mathrm{NiO}$ particles, and NiOx/SA-028 and $\mathrm{NiOx} / \mathrm{SA}-047$ exhibited a medium-strength metal oxide-support interaction.

Figure 4 shows the Ni 2p XPS spectra of the NiOx/SA catalysts prepared in this study. The Ni $2 \mathrm{p}$ species can be deconvoluted in three different states, corresponding to interfacial phases of $\mathrm{NiO}$, $\mathrm{NiOx}$, and $\mathrm{NiAl}_{2} \mathrm{O}_{4}$, the $\mathrm{Ni} 2 \mathrm{p}_{3 / 2}$ peaks of which were located at 854-856, 856-857, and 857-858 eV, respectively (Table 3 ). $\mathrm{Ni}^{\delta+}$ by NiOx was correlated with the higher binding-energy changes of $\mathrm{Ni}^{2+}$ due to the adjacent nickel oxide, silica, and alumina structures [58]. NiOx/SA-386 exhibited lower binding energies of $\mathrm{Ni}^{2+}$ (from $\mathrm{NiO}$ ) and $\mathrm{Ni}^{\delta+}$ (from $\mathrm{NiOx}$ ) due to the increased extent of electron transfer from neighboring silica in the SA structure to nickel species observed with increasing silica content. 
Moreover, the binding energy of $\mathrm{Ni}^{2+}$ in $\mathrm{NiAl}_{2} \mathrm{O}_{4}$ was increased due to electron transfer from nickel species to the neighboring alumina in the SA structure, which was promoted by the strong interaction between the surface nickel and the alumina support. The proportion of $\mathrm{Ni}^{2+}$ present as $\mathrm{NiAl}_{2} \mathrm{O}_{4}$ decreased from NiOx/SA-001 to NiOx/SA-386 due to the concomitantly increasing Si/Al ratio (Table 3), implying a simultaneous decrease in the surface nickel oxide-support alumina interaction strength.
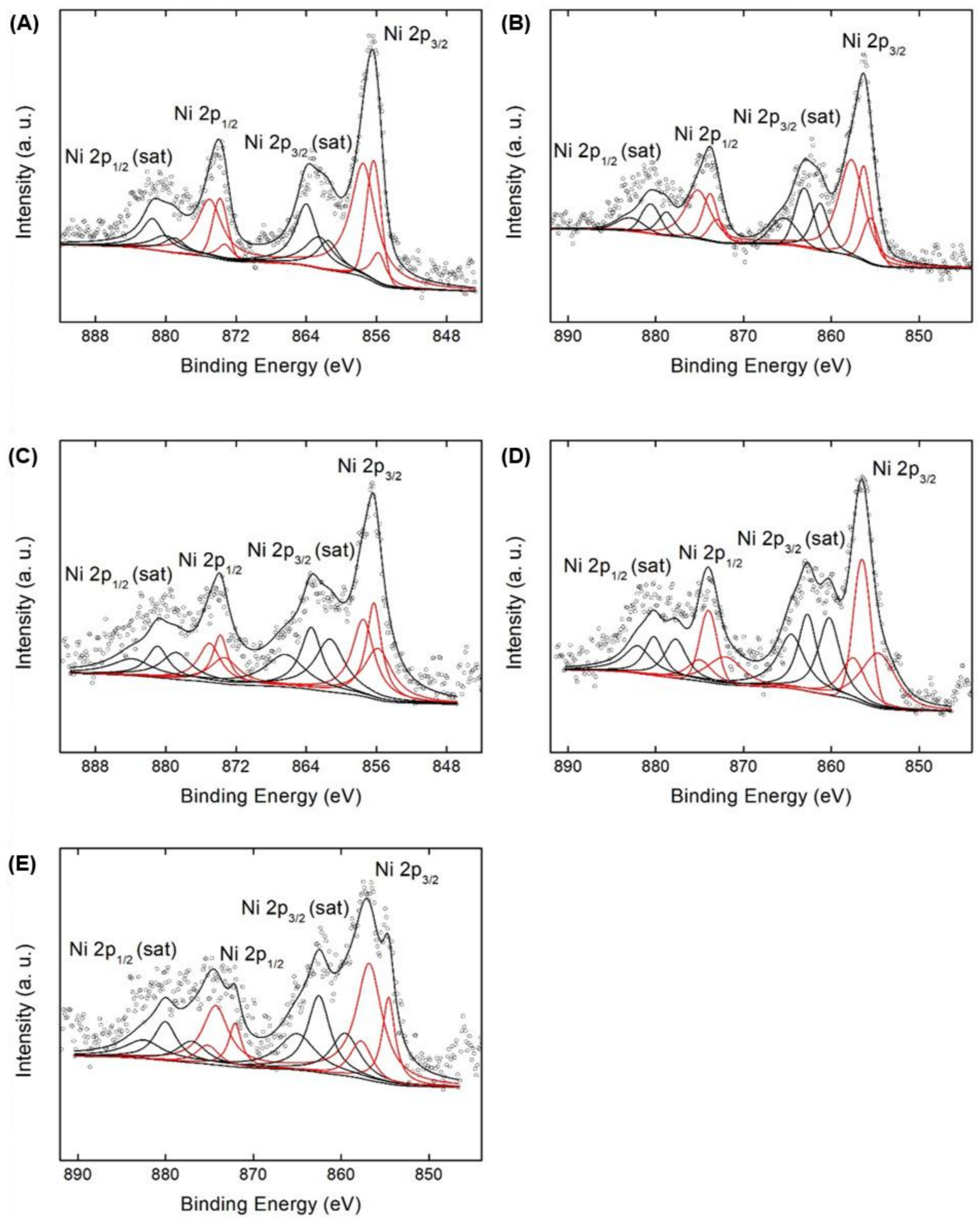

Figure 4. XPS spectra of Ni 2p obtained from (A) NiOx/SA-001, (B) NiOx/SA-007, (C) NiOx/SA-028, (D) $\mathrm{NiOx} / \mathrm{SA}-047$, and (E) NiOx/SA-386. 
As the metal oxide-support interaction changed, the number of aggregated nickel oxides also changed. The $\mathrm{Ni}^{2+} / \mathrm{Ni}^{\delta+}$ ratio was controlled in the following order: NiOx/SA-386 $<\mathrm{NiOx} / \mathrm{SA}-001<$ $\mathrm{NiOx} / \mathrm{SA}-007<\mathrm{NiOx} / \mathrm{SA}-047<\mathrm{NiOx} / \mathrm{SA}-028$. $\mathrm{The}^{\mathrm{Ni}}{ }^{2+} / \mathrm{Ni}^{8+}$ ratio can be correlated with catalytic performance (see below) because $\mathrm{Ni}^{2+}$ derived from $\mathrm{NiO}$ as the lowest binding energy in the nickel oxidation states can be most advantageous for the catalytic performance as one of active sites in this study. The weakened metal oxide-support interaction was also confirmed by the presence of aggregated nickel oxides on the SA surface in NiOx/SA-047 and NiOx/SA-386, as determined by EDS maps (Figure S1).

Table 3. Relative intensities of XPS spectra of $\mathrm{Ni} 2 \mathrm{p}_{3 / 2}$.

\begin{tabular}{|c|c|c|c|c|c|}
\hline Catalyst & & $\begin{array}{c}\mathrm{Ni}^{2+} \\
\text { by } \mathrm{NiO}\end{array}$ & $\begin{array}{c}\mathrm{Ni}^{\delta+} \\
\text { by } \mathrm{NiOx}\end{array}$ & $\begin{array}{c}\mathrm{Ni}^{2+} \\
\text { by } \mathrm{NiAl}_{2} \mathrm{O}_{4}\end{array}$ & $\begin{array}{l}\mathrm{Ni}^{2+} \text { from } \mathrm{NiO} / \\
\mathrm{Ni}^{\delta+} \text { from } \mathrm{NiOx}\end{array}$ \\
\hline \multirow{3}{*}{$\mathrm{NiOx} / \mathrm{SA}-001$} & Binding energy (eV) & 855.8 & 856.3 & 857.5 & \multirow{3}{*}{0.38} \\
\hline & Area (a.u.) & 363.8 & 969.7 & 2206.6 & \\
\hline & Area ratio (\%) & 10.3 & 27.4 & 62.3 & \\
\hline \multirow{3}{*}{$\mathrm{NiOx/SA-007}$} & Binding energy $(\mathrm{eV})$ & 855.5 & 856.3 & 857.7 & \multirow{3}{*}{0.41} \\
\hline & Area (a.u.) & 402.5 & 973.2 & 1817.1 & \\
\hline & Area ratio (\%) & 12.6 & 30.5 & 56.9 & \\
\hline \multirow{3}{*}{$\mathrm{NiOx/SA-028}$} & Binding energy $(\mathrm{eV})$ & 855.8 & 856.3 & 857.5 & \multirow{3}{*}{0.94} \\
\hline & Area (a.u.) & 901.2 & 909.8 & 1063.5 & \\
\hline & Area ratio (\%) & 30.2 & 32.2 & 37.6 & \\
\hline \multirow{3}{*}{$\mathrm{NiOx/SA-047}$} & Binding energy (eV) & 854.6 & 856.5 & 857.5 & \multirow{3}{*}{0.92} \\
\hline & Area (a.u.) & 975.1 & 1057.8 & 583.2 & \\
\hline & Area ratio $(\%)$ & 37.3 & 40.4 & 22.3 & \\
\hline \multirow{3}{*}{ NiOx/SA-386 } & Binding energy $(\mathrm{eV})$ & 854.6 & 856.8 & 857.7 & \multirow{3}{*}{0.37} \\
\hline & Area (a.u.) & 458.9 & 1241.0 & 307.6 & \\
\hline & Area ratio (\%) & 22.9 & 61.8 & 15.3 & \\
\hline
\end{tabular}

\subsection{Acid Site Properties of NiOx/SA Catalysts}

According to the plausible mechanism, L.A sites formed by nickel oxides and SA derived B.A sites can catalyze ethylene oligomerization $[22,24,71]$. To be specific, ethylene is believed to be activated by L.A by nickel ion species such as $\mathrm{Ni}^{2+}$ and $\mathrm{Ni}^{\delta+}$, with isomerization (including hydrogen transfer) propagating and terminating at B.A sites. Since both of the above sites were thought to be involved in ethylene oligomerization, the number of acid sites can be considered to produce the oligomers as decreasing in the order of NiOx/SA-047 $>$ NiOx/SA-028 > NiOx/SA-386 > NiOx/SA-007 > NiOx/SA-001 and NiOx/SA-047 > NiOx/SA-028 > NiOx/SA-386 NiOx/SA-007 > NiOx/SA-001 determined by $\mathrm{NH}_{3}$-TPD and $p y$-FT-IR, respectively (Figure 5 and Table 4). To investigate the effect of specific acid sites, we also compared the B.A/L.A ratios of $\mathrm{NiOx} / \mathrm{SA}$ catalysts characterized by $p y$-FT-IR, which revealed that the B.A/L.A ratio increased in the order of Ni/SA-001 Ni/SA-007 $<\mathrm{Ni} / \mathrm{SA}-028<\mathrm{Ni} / \mathrm{SA}-386<$ Ni/SA-047 (Table 4). 

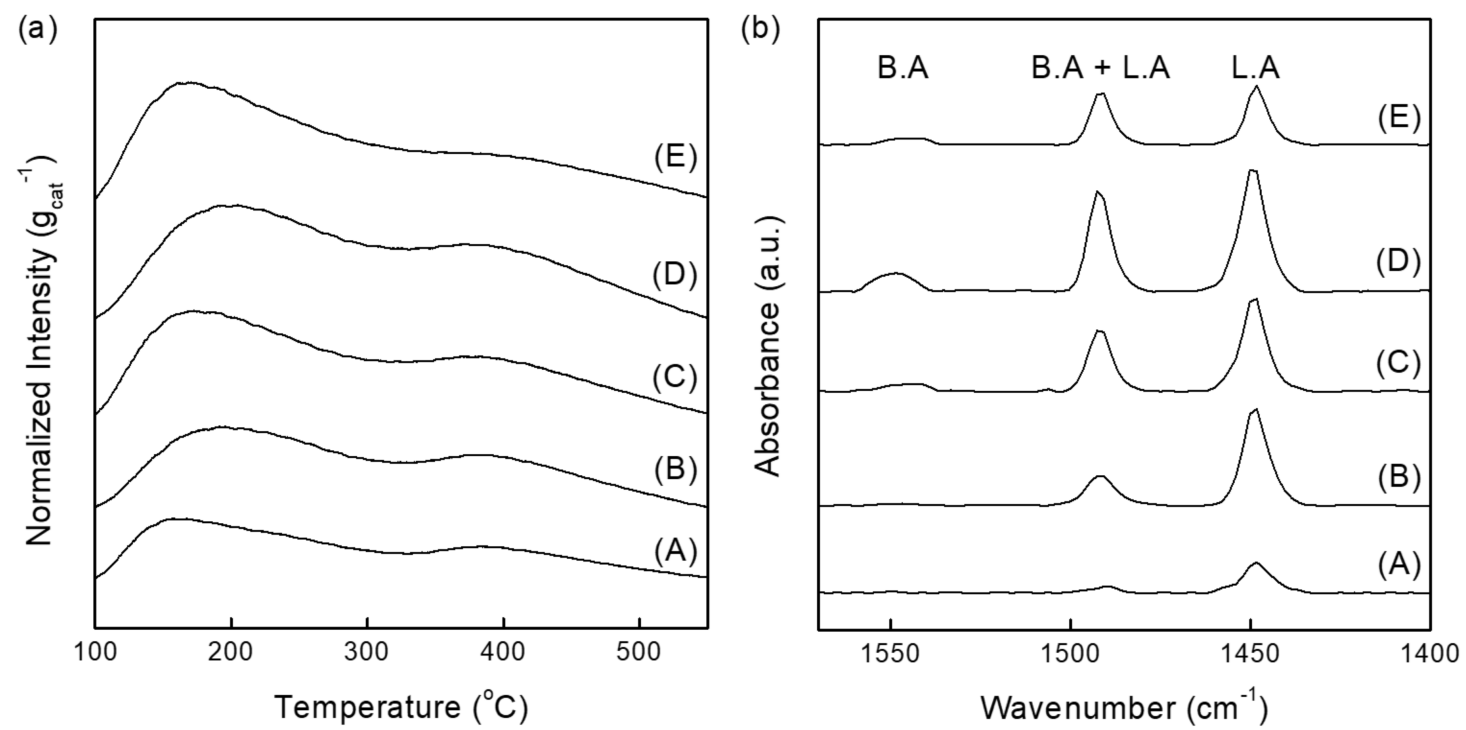

Figure 5. (a) $\mathrm{NH}_{3}$-TPD profiles and (b) py-FT-IR spectra of (A) NiOx/SA-001, (B) NiOx/SA-007, (C) NiOx/SA-028, (D) NiOx/SA-047, and (E) NiOx/SA-386.

Table 4. Acid site properties determined by $\mathrm{NH}_{3}$-TPD and pyridine-FT-IR ( $p y$-FT-IR).

\begin{tabular}{|c|c|c|c|c|}
\hline \multirow{2}{*}{ Catalyst } & \multirow{2}{*}{$\begin{array}{l}\mathrm{NH}_{3}-\mathrm{TPD} \\
\left(\mathrm{mmol} / \mathrm{g}_{\mathrm{cat}}\right)\end{array}$} & \multicolumn{3}{|c|}{$p y$-FT-IR } \\
\hline & & B.A (mmol/g $\left.\mathrm{g}_{\text {cat }}\right)$ & L.A (mmol/gat) & B.A/L.A \\
\hline NiOx/SA-001 & 0.49 & 0.00 & 0.02 & 0.00 \\
\hline NiOx/SA-007 & 0.74 & 0.00 & 0.06 & 0.00 \\
\hline $\mathrm{NiOx} / \mathrm{SA}-028$ & 0.92 & 0.01 & 0.08 & 0.13 \\
\hline NiOx/SA-047 & 1.06 & 0.03 & 0.12 & 0.25 \\
\hline $\mathrm{NiOx} / \mathrm{SA}-386$ & 0.91 & 0.01 & 0.05 & 0.20 \\
\hline
\end{tabular}

\subsection{Ethylene Oligomerization over NiOx/SA Catalysts}

Ethylene oligomerization was performed on the five $\mathrm{NiOx} / \mathrm{SA}$ catalysts with different $\mathrm{Si} / \mathrm{Al}$ ratios (0.01-3.86) at $200{ }^{\circ} \mathrm{C}, 10 \mathrm{bar}$, and $0.375 \mathrm{~h}^{-1}$ WHSV, which are identical to those in our previous study $[2,53]$. Figure 6 shows the ethylene conversion and selectivity to products. The average ethylene conversion and selectivity to $\mathrm{C} 10+$ are compared with the characterization results of XPS, $\mathrm{NH}_{3}-\mathrm{TPD}$, and $p y$-FT-IR in Figure 7. After the entire reaction time of $16 \mathrm{~h}$, the average ethylene conversion decreased in the order of NiOx/SA-047 $(89 \%)>$ NiOx/SA-028 $(84 \%)>$ NiOx/SA-007 $(74 \%)>$ NiOx/SA-001 $(60 \%)>\mathrm{NiOx} / \mathrm{SA}-386(22 \%)$. NiOx/SA-386 achieved not only the lowest ethylene conversion but also the lowest selectivity to $\mathrm{C} 10+$. As discussed above, despite the acid site density of NiOx/SA-386 not being the lowest, it showed weak metal oxide-support interaction, which induced nickel oxide aggregation to produce large particles. Therefore, reduced $\mathrm{NiOx}$ active sites should lead to the lower catalytic activity. On the other hand, NiOx/SA-001 and NiOx/SA-007 exhibited the medium level of ethylene conversion among the five catalysts. Those catalysts featured highly dispersed nickel oxides species on SA support determined by $\mathrm{H}_{2}$-TPR (Figure 3) and EDS mapping images of HAADF-TEM (Figure S1). This indicates a strong metal oxide-support (especially alumina species because of its relatively large amount) interaction that incorporated Ni species into the alumina structure, leading to producing a large amount of deactivated nickel oxide species for ethylene activation by the formation of surface $\mathrm{NiAl}_{2} \mathrm{O}_{4}$. In other words, ethylene can be activated by a nickel oxide, especially $\mathrm{Ni}^{2+}$ from $\mathrm{NiO}$. We should note here that NiOx/SA-028 and NiOx/SA-047 exhibiting a medium metal oxide-support interaction resulted in the best catalytic performance among the catalysts. As shown in Figure 7, $\mathrm{Ni}^{2+}$ from $\mathrm{NiO} / \mathrm{Ni}^{\delta+}$ from the $\mathrm{NiO}_{x}$ ratio of those two catalysts were the highest and second highest, respectively. In addition, $\mathrm{NiOx} / \mathrm{SA}-047$ had the highest acid site density and B.A/L.A ratio. From the 
overall results, it can be concluded that the ethylene oligomerization performance can be strongly influenced by the metal oxide-support interaction strength as well as acid site properties.
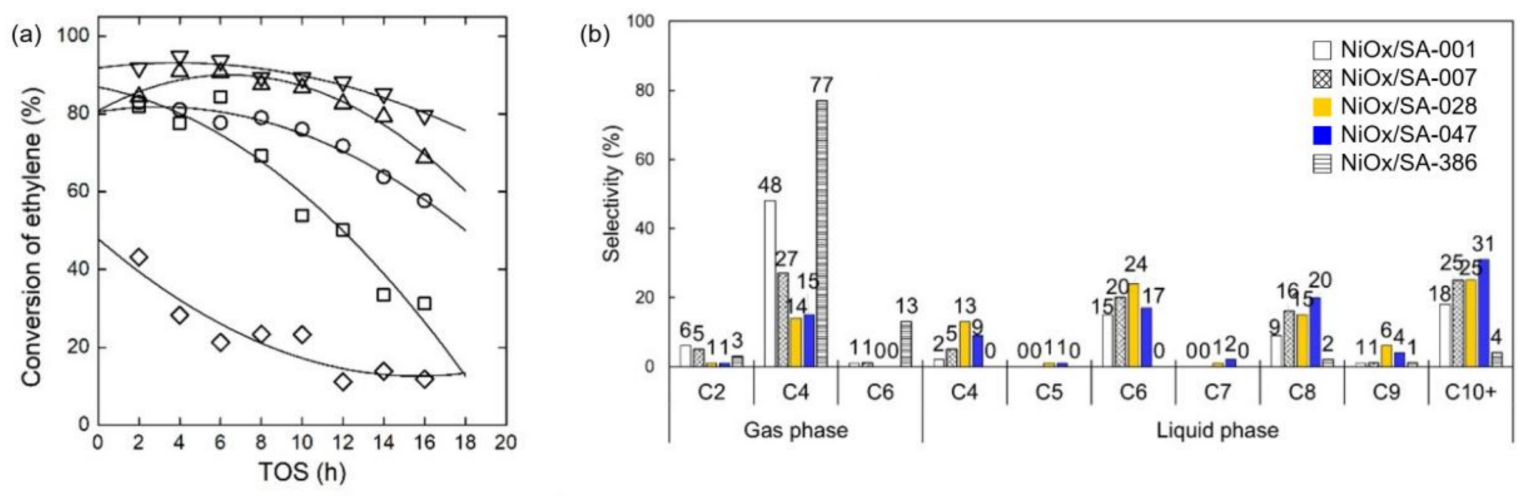

$\square \mathrm{NiOx/SA}-001, \bigcirc \mathrm{NiOx} / \mathrm{SA}-007, \triangle \mathrm{NiOx/SA}-028$, $\nabla \mathrm{NiOx} / \mathrm{SA}-047, \diamond \mathrm{NiOx/SA-386}$

Figure 6. (a) Ethylene conversion as a function of time on stream (TOS) over NiOx/SA-001, NiOx/SA-007, $\mathrm{NiOx} / \mathrm{SA}-028, \mathrm{NiOx} / \mathrm{SA}-047$, and NiOx/SA-386 at $00{ }^{\circ} \mathrm{C}, 10 \mathrm{bar}$, and $0.375 \mathrm{~h}^{-1}$ WHSV and (b) selectivity to products of gas (C2-C6) and liquid phases (C4-C10+) obtained after $16 \mathrm{~h}$ on stream.
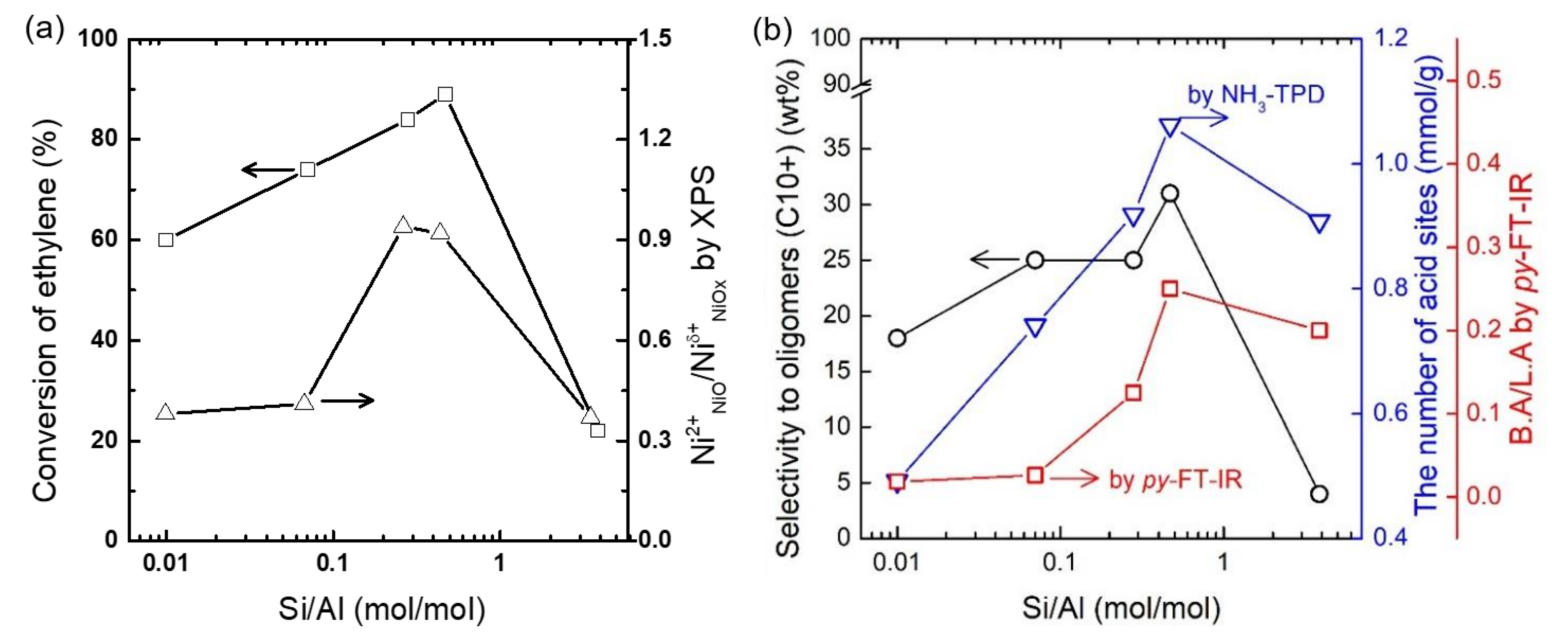

Figure 7. Comparisons between (a) ethylene conversion and $\mathrm{Ni}^{2+} / \mathrm{Ni}^{\delta+}$ ratio determined by XPS and (b) selectivity to $\mathrm{C} 10+$ oligomers and total number of acid sites and B.A/L.A ratio determined by $\mathrm{NH}_{3}$-TPD and $p y$-FT-IR, respectively. Conversion and selectivity are the average values obtained after the entire reaction time of $16 \mathrm{~h}$ performed at $200{ }^{\circ} \mathrm{C}, 10 \mathrm{bar}$, and $0.375 \mathrm{~h}^{-1} \mathrm{WHSV}$. The $\mathrm{Ni}^{2+} / \mathrm{Ni}^{\delta+}$ ratio was derived from the deconvoluted area ratio of $\mathrm{NiO}$ and $\mathrm{NiO}_{x} \mathrm{Ni} 2 \mathrm{p}_{3 / 2}$ XPS spectra.

\section{Materials and Methods}

\subsection{Preparation of NiOx/SA Catalysts}

Four Siral series (Siral-1, -10, -30, and -40) silica-aluminas and one other silica-alumina were purchased from Sasol and Aldrich, respectively. Those were calcined at $550{ }^{\circ} \mathrm{C}$ for $5 \mathrm{~h}$ in an air flow, ground, and sieved to smaller than $150 \mu \mathrm{m}$, being subsequently impregnated with $4 \mathrm{wt} \%$ of $\mathrm{Ni}$ by an incipient wetness method using $\mathrm{Ni}\left(\mathrm{NO}_{3}\right)_{2} \cdot 6 \mathrm{H}_{2} \mathrm{O}$ (Samchun, $98 \%$ ) as a precursor. The obtained catalysts were dried for $5-6 \mathrm{~h}$ at $120^{\circ} \mathrm{C}$, and calcined at $550{ }^{\circ} \mathrm{C}$ for $5 \mathrm{~h}$ under flowing air.

\subsection{Analytical Methods}

Powder XRD patterns were recorded at $40 \mathrm{kV}$ and $40 \mathrm{~mA}$ using a diffractometer equipped with a multipurpose high-temperature probe (D/MAX-2500PC, Rigaku) and a $\mathrm{Cu} \mathrm{K}_{\alpha 1}$ source $(\lambda=1.54056 \AA)$. Scanning was performed in a $2 \theta$ range of $20-80^{\circ}$ at a rate of $1.5 \mathrm{deg} / \mathrm{min}$. Elemental analysis and $\mathrm{N}_{2}$ 
sorption experiments of all the catalysts were carried out by a Thermo Fisher Scientific iCAP 7400 duo inductively coupled plasma-atomic emission spectrometer and a Micromeritics ASAP 2020 analyzer, respectively. The $\mathrm{N}_{2}$ sorption isotherms and pore size distribution curves are described in Figure $\mathrm{S} 2$.

UV-DRS spectra were obtained in the range of 300-800 $\mathrm{nm}$ with a step of $1 \mathrm{~nm}$ using a Lambda 1050 (Perkin Elmer) UV-vis spectrophotometer. The oxidation states of catalyst components were evaluated by XPS (PHI 5000 VersaProbe, Ulvac-PHI) using a monochromated Al $\mathrm{K}_{\alpha}$ source $(1486.6 \mathrm{eV})$, with calibration performed using the $\mathrm{C} 1 \mathrm{~s}$ binding energy at $284.6 \mathrm{eV}$.

$\mathrm{H}_{2}$-TPR and $\mathrm{NH}_{3}$-TPD were carried out using a BELCAT-B instrument equipped with a thermal conductivity detector (TCD) at a ramping rate of $5{ }^{\circ} \mathrm{C} / \mathrm{min}$ in temperature ranges of $50-950{ }^{\circ} \mathrm{C}$ using $\mathrm{H}_{2}(99.999 \%)$ and $\mathrm{Ar}(99.999 \%)$, and $100-550{ }^{\circ} \mathrm{C}$ using $\mathrm{NH}_{3}(29.8 \%$ with He balance) and $\mathrm{He}$ $(99.999 \%)$, respectively.

py-FT-IR spectra were obtained by pyridine (Janssen Chimica, 99\%) and a Thermo Scientific Nicolet 6700 FT-IR spectrometer equipped with an MCT-A detector. Each spectrum represented the average of 100 scans performed in the range of $1400-1700 \mathrm{~cm}^{-1}$ with a resolution of $4 \mathrm{~cm}^{-1}$, as described previously [72]. A self-pelletized catalyst (16-25 mg and $1.3 \mathrm{~cm}$ diameter) was evacuated at $300^{\circ} \mathrm{C}$ and pressures below $1 \mathrm{mbar}$ for $1 \mathrm{~h}$ in an IR cell equipped with a $\mathrm{CaF}_{2}$ window connected to a Schlenk line for removing any physisorbed moisture. Prior to pyridine adsorption, a background spectrum was collected with the evacuated pellet. Excess pyridine physisorbed on the catalyst surface at room temperature was removed by $1 \mathrm{~h}$ evacuation at room temperature and pressure below $1 \mathrm{mbar}$. The treated pellet was further evacuated at $200{ }^{\circ} \mathrm{C}$ below $1 \mathrm{mbar}$ for $1 \mathrm{~h}$ and then cooled to room temperature for recording the FT-IR spectra. Densities of the B.A and L.A sites were calculated using distinct peaks at around 1550 and $1450 \mathrm{~cm}^{-1}$, respectively, using the equations of Emeis [73].

HAADF images and EDS elemental maps and the spectra of nickel oxide particles were obtained using an FEI Titan double Cs-corrected TEM (Titan Cubed G2 60-300, FEI) operating at $300 \mathrm{kV}$. Z-contrast conditions were achieved using a probe semi-angle of $19.3 \mathrm{mrad}$ and an inner collection angle of the detector of $40 \mathrm{mrad}$. The EDS maps and spectra were obtained by an FEI Super-X detector equipped with four silicon drift detectors.

\subsection{Ethylene Oligomerization}

Ethylene oligomerization was performed in a fixed bed reactor filled with a catalyst $(1 \mathrm{~g}$, 150-250 $\mu \mathrm{m}$ ) pretreated at $550^{\circ} \mathrm{C}$ under $\mathrm{He}(99.9 \%)$ gas flow for $8 \mathrm{~h}$. Subsequently, the reactor was filled with ethylene $(99.95 \%, 5 \mathrm{~mL} / \mathrm{min}, 10 \mathrm{bar}$, room temperature) and the oligomerization was performed at $200{ }^{\circ} \mathrm{C}$ and $0.375 \mathrm{~h}^{-1} \mathrm{WHSV}$ for $16 \mathrm{~h}$. Ethylene conversion and gas phase products $(\leq \mathrm{C} 6)$ were quantified online in a Younglin YL6500 gas chromatograph (GC) equipped with a TCD connected to a 60/80 Carboxene 1000 packed column ( $15 \mathrm{ft} \times 1 / 8 \mathrm{in} \times 2.1 \mathrm{~mm}$, Supelco) with $\mathrm{Ar}(99.9 \%, 2 \mathrm{~mL} / \mathrm{min})$ as an internal standard and a flame ionization detector (FID) using an Rt-Alumina BOND/ $\mathrm{Na}_{2} \mathrm{SO}_{4}$ capillary column $(50 \mathrm{~m} \times 0.53 \mathrm{~mm} \times 10 \mu \mathrm{m}$, RESTEK), respectively. Liquid products $(\geq \mathrm{C} 4)$ were collected at $-2.5^{\circ} \mathrm{C}$ using a separator and quantified by another GC-FID (YL6500 GC, Younglin) equipped with capillary columns connected in series (RTX-5 DHA ( $5 \%$ diphenyl, $5 \mathrm{~m} \times 0.25 \mathrm{~mm} \times 0.5 \mu \mathrm{m}$, RESTEK) + RTX-100 DHA $(100 \mathrm{~m} \times 0.25 \mathrm{~mm} \times 0.5 \mu \mathrm{m}$, RESTEK)). The liquid product was analyzed in an offline mode right after the reaction every $16 \mathrm{~h}$. Ethylene conversion and selectivity to product $i$ were determined using the following equations. Conversion $(\%)=\left(F_{i}-F_{f}\right) / F_{i} \times 100$ where $F_{i}$ and $F_{f}$ are the mass flow rate of ethylene inlet and outlet stream, respectively. Selectivity $(\%)=P_{i} /\left(F_{i}-F_{f}\right) \times 100$ where $P_{i}$ is the mass flow rate of product $i$.

\section{Conclusions}

In this study, five $\mathrm{NiOx} / \mathrm{SA}$ catalysts with different $\mathrm{Si} / \mathrm{Al}$ ratios but similar Ni contents were prepared, characterized, especially for the interaction strength between NiOx and the SA support, and their activity for oligomerization of ethylene under identical reaction conditions was investigated. The strong interaction observed in NiOx/SA-001 and NiOx/SA-007 induced the formation of surface 
nickel aluminate and the reduction of active $\mathrm{NiOx}$ species, and thus hindered the catalytic conversion of ethylene. NiOx/SA-386, featuring a weak metal oxide-support interaction, showed low catalytic activity due to the aggregation of $\mathrm{NiOx}$ particles on the surface, despite the relatively large number of acid sites and high B.A/L.A ratio. In the case of NiOx/SA-028 and NiOx/SA-047, their medium metal oxide-support interaction resulted in optimal catalytic performance due to the increasing $\mathrm{Ni}^{2+} / \mathrm{Ni}^{\delta+}$ ratio and acid site density. The overall results demonstrate that the activity of NiOx/SA catalysts in ethylene oligomerization depends on electronic property of nickel oxide as well as their acidity. The high performance of ethylene oligomerization requires high amount of both active nickel oxides and acid sites at the medium interaction strength between nickel oxide and silica-alumina support.

Supplementary Materials: The following are available online at http://www.mdpi.com/2073-4344/9/11/933/s1, Figure S1: HAADF-TEM images, EDS maps, and EDS spectra of NiOx/SA-001, NiOx/SA-007, NiOx/SA-028, $\mathrm{NiOx} / \mathrm{SA}-047$, and NiOx/SA-386, Figure S2: $\mathrm{N}_{2}$ adsorption-desorption isotherms of NiOx/SA-001, -007, -028, -047, and -386 and pore size distribution curves of the corresponding catalysts calculated using the BJH formalism from the $\mathrm{N}_{2}$ desorption branch isotherm.

Author Contributions: Conceptualization, D.W.H. and H.-J.C.; Experiment, J.S.Y. and Y.K.; Data analysis, J.S.Y., M.B.P., and H.-J.C.; Writing-original draft preparation, J.S.Y.; Writing-review and editing, M.B.P.; Supervision, H.-J.C.; Project administration, Y.K.; Funding acquisition, D.W.H. and H.-J.C.

Funding: This work was supported by the research programs of the Korea Institute of Energy Technology Evaluation and Planning (KETEP) funded by Ministry of Trade, Industry and Energy (20153010092090 and 20181110200060) and Basic Science Research Program through the National Research Foundation of Korea (NRF) funded by the Ministry of Science \& ICT (2019R1F1A1061214).

Conflicts of Interest: The authors declare no conflict of interest.

\section{References}

1. Chae, H.-J.; Kim, T.-W.; Moon, Y.-K.; Kim, H.-K.; Jeong, K.-E.; Kim, C.-U.; Jeong, S.-Y. Butadiene production from bioethanol and acetaldehyde over tantalum oxide-supported ordered mesoporous silica catalysts. Appl. Catal. B Environ. 2014, 150-151, 596-604. [CrossRef]

2. Babu, B.H.; Lee, M.; Hwang, D.W.; Kim, Y.; Chae, H.-J. An integrated process for production of jet-fuel range olefins from ethylene Ni-AlSBA-15 and Amberlyst-35 catalysts. Appl. Catal. A Gen. 2017, 530, 48-55. [CrossRef]

3. Jiang, P.; Wu, X.; Zhu, L.; Jin, F.; Liu, J.; Xia, T.; Wang, T.; Li, Q. Production of jet fuel range paraffins by low temperature polymerization of gaseous light olefins using ionic liquid. Energy Convers. Manag. 2016, 120, 338-345. [CrossRef]

4. Zhang, H.; Li, X.; Zhang, Y.; Lin, S.; Li, G.; Chen, L.; Fang, Y.; Xin, H.; Li, X. Ethylene oligomerization over heterogeneous catalysts. Energy Environ. Focus 2014, 3, 246-256. [CrossRef]

5. Breuil, P.-A.R.; Magna, L.; Olivier-Bourbigou, H. Role of homogeneous catalysis in oligomerization of olefins: Focus on selected examples based on group 4 to group 10 transition metal complexes. Catal. Lett. 2015, 145, 173-192. [CrossRef]

6. Huang, W.; Gong, F.; Fan, M.; Zhai, Q.; Hong, C.; Li, Q. Production of light olefins by catalytic conversion of lignocellulosic biomass with HZSM-5 zeolite impregnated with 6wt\% lanthanum. Bioresour. Technol. 2012, 121, 248-255. [CrossRef]

7. Ding, X.; Li, C.; Yang, C. Study on the oligomerization of ethylene in fluidized catalytic cracking (FCC) dry gas over metal-loaded HZSM-5 catalysts. Energy Fuels 2010, 24, 3760-3763. [CrossRef]

8. Yamamura, M.; Chaki, K.; Wakatsuki, T.; Okado, H.; Fujimoto, K. Synthesis of ZSM-5 zeolite with small crystal size and its catalytic performance for ethylene oligomerization. Zeolites 1994, 14, 643-649. [CrossRef]

9. Ying, L.; Zhu, J.; Cheng, Y.; Wang, L.; Li, X. Kinetic modeling of $\mathrm{C}_{2}-\mathrm{C}_{7}$ olefins interconversion over ZSM-5 catalyst. J. Ind. Eng. Chem. 2016, 33, 80-90. [CrossRef]

10. Chen, C.S.H.; Bridger, R.F. Shape-selective oligomerization of alkenes to near-linear hydrocarbons by zeolite catalysis. J. Catal. 1996, 161, 687-693. [CrossRef]

11. de Souza, M.O.; Mendes, F.M.T.; de Souza, R.F.; dos Santos, J.H.Z. XPS characterization of nickel-acetylacetonate impregnated in NaX and NaY zeolites. Microporous Mesoporous Mater. 2004, 69, 217-221. [CrossRef] 
12. Lallemand, M.; Finiels, A.; Fajula, F.; Hulea, V. Catalytic oligomerization of ethylene on Ni-containing dealuminated Y zeolites. Appl. Catal. A Gen. 2006, 301, 196-201. [CrossRef]

13. Hulea, V.; Lallemand, M.; Finiels, A.; Fajula, F. Catalytic oligomerization of ethylene over Ni-containing MCM-22, MCM-41 and USY. Stud. Surf. Sci. Catal. 2005, 158, 1621-1628.

14. Ng, F.T.T.; Creaser, D.C. Ethylene dimerization over modified nickel exchanged Y-zeolite. Appl. Catal. A Gen. 1994, 119, 327-339. [CrossRef]

15. Martínez, A.; Arribas, M.A.; Concepción, P.; Moussa, S. New bifunctional Ni-H-beta catalysts for the heterogeneous oligomerization of ethylene. Appl. Catal. A Gen. 2013, 467, 509-518. [CrossRef]

16. Lallemand, M.; Rusu, O.A.; Dumitriu, E.; Finiels, A.; Fajula, F.; Hulea, V. NiMCM-36 and NiMCM-22 catalysts for the ethylene oligomerization effect of zeolite texture and nickel cations/acid sites ratio. Appl. Catal. A Gen. 2008, 338, 37-43. [CrossRef]

17. Lallemand, M.; Rusu, O.A.; Dumitriu, E.; Finiels, A.; Fajula, F.; Hulea, V. Ni-MCM-36 and Ni-MCM-22 catalysts for the ethylene oligomerization. Stud. Surf. Sci. Catal. 2008, 174, 1139-1142.

18. Andrei, R.D.; Popa, M.I.; Fajula, F.; Hulea, V. Heterogeneous oligomerization of ethylene over highly active and stable Ni-AlSBA-15 mesoporous catalysts. J. Catal. 2015, 323, 76-84. [CrossRef]

19. Lin, S.; Shi, L.; Zhang, H.; Zhang, N.; Yi, X.; Zheng, A.; Li, X. Tuning the pore structure of plug-containing Al-SBA-15 by post-treatment and its selectivity for $\mathrm{C}_{16}$ olefin in ethylene oligomerization. Microporous Mesoporous Mater. 2014, 184, 151-161. [CrossRef]

20. de Souza, M.O.; Rodrigues, L.R.; Gauvin, R.M.; de Souza, R.F.; Pastore, H.O.; Gengembre, L.; Ruiz, J.A.C.; Gallo, J.M.R.; Milanesi, T.S.; Milani, M.A. Support effect in ethylene oligomerization mediated by heterogenized nickel catalysts. Catal. Commun. 2010, 11, 597-600. [CrossRef]

21. Lallemand, M.; Finiels, A.; Fajula, F.; Hulea, V. Nature of the active sites in ethylene oligomerization catalyzed by Ni-containing molecular sieves: Chemical and IR spectral investigation. J. Phys. Chem. C 2009, 113, 20360-20364. [CrossRef]

22. de Souza, M.O.; Rodrigues, L.R.; Pastore, H.O.; Ruiz, J.A.C.; Gengembre, L.; Gauvin, R.M.; de Souza, R.F. A nano-organized ethylene oligomerization catalyst: Characterization and reactivity of the $\mathrm{Ni}(\mathrm{MeCN})_{6}\left(\mathrm{BF}_{4}\right)_{2} /[\mathrm{Al}]-\mathrm{MCM}-41 / \mathrm{AlEt}_{3}$ system. Microporous Mesoporous Mater. 2006, 96, 109-114. [CrossRef]

23. Hulea, V.; Fajula, F. Ni-exchanged AlMCM-41-An efficient bifunctional catalyst for ethylene oligomerization. J. Catal. 2004, 225, 213-222. [CrossRef]

24. Moussa, S.; Arribas, M.A.; Concepción, P.; Martínez, A. Heterogeneous oligomerization of ethylene to liquids on bifunctional Ni-based catalysts: The influence of support properties on nickel speciation and catalytic performance. Catal. Today 2016, 277, 78-88. [CrossRef]

25. Nicolaides, C.P.; Scurrell, M.S.; Semano, P.M. Nickel silica-alumina catalysts for ethene oligomerization-control of the selectivity to 1-alkene products. Appl. Catal. A Gen. 2003, 245, 43-53. [CrossRef]

26. Heveling, J.; Nicolaides, C.P. Chain-length distributions obtained over nickel(II)-exchanged or impregnated silica-alumina catalysts for the oligomerization of lower alkenes. Catal. Lett. 2006, 107, 117-121. [CrossRef]

27. Heveling, J.; Nicolaides, C.P.; Scurrell, M.S. Catalysts and conditions for the highly efficient, selective and stable heterogeneous oligomerization of ethylene. Appl. Catal. A Gen. 1998, 173, 1-9. [CrossRef]

28. Espinoza, R.L.; Snel, R.; Korf, C.J.; Nicolaides, C.P. Catalytic oligomerization of ethene over nickel-exchanged amorphous silica-aluminas; effect of the acid strength of the support. Appl. Catal. 1987, 29, 295-303. [CrossRef]

29. Espinoza, R.L.; Nicolaides, C.P.; Korf, C.J.; Snel, R. Catalytic oligomerization of ethene over nickel-exchanged amorphous silica-alumina; effect of the nickel concentration. Appl. Catal. 1987, 31, 259-266. [CrossRef]

30. Espinoza, R.L.; Korf, C.J.; Nicolaides, C.P.; Snel, R. Catalytic oligomerization of ethene over nickel-exchanged amorphous silica-alumina; effect of the reaction conditions and modelling of the reaction. Appl. Catal. 1987, 29, 175-184. [CrossRef]

31. Davydov, A.A.; Kantcheva, M.; Chepotko, M.L. FTIR spectroscopic study on nickel(II)-exchanged sulfated alumina: Nature of the active sites in the catalytic oligomerization of ethene. Catal. Lett. 2002, 83, 97-108. [CrossRef]

32. Zhang, Q.; Kantcheva, M.; Lana, I.G.D. Oligomerization of ethylene in a slurry reactor using a nickel/sulfated alumina catalyst. Ind. Eng. Chem. Res. 1997, 36, 3433-3438. [CrossRef]

33. Zhang, Q.; Lana, I.G.D. An analysis of mass transfer and kinetics during ethylene oligomerization over nickel/sulfated alumina catalyst in a slurry reactor. Chem. Eng. Sci. 1997, 52, 4187-4195. [CrossRef] 
34. Cai, T.; Zang, L.; Qi, A.; Wang, D.; Cao, D.; Li, L. Propene oligomerization catalyst derived from nickel sulfate supported on $\gamma$-alumina. Appl. Catal. 1991, 69, 1-13. [CrossRef]

35. Lavrenov, A.V.; Buluchevskii, E.A.; Moiseenko, M.A.; Drozdov, V.A.; Arbuzov, A.B.; Gulyaeva, T.I.; Likholobov, V.A.; Duplyakin, V.K. Chemical composition optimization and characterization of the $\mathrm{NiO} / \mathrm{B}_{2} \mathrm{O}_{3}-\mathrm{Al}_{2} \mathrm{O}_{3}$ system as a catalyst for ethylene oligomerization. Kinet. Catal. 2010, 51, 404-409. [CrossRef]

36. Sohn, J.R.; Lee, S.Y. High catalytic activity of $\mathrm{NiO}-\mathrm{ZrO}_{2}$ modified with $\mathrm{WO}_{3}$ for ethylene dimerization. Appl. Catal. A Gen. 1997, 164, 127-140. [CrossRef]

37. Sohn, J.R.; Shin, D.C. New catalyst of $\mathrm{NiO}-\mathrm{ZrO}_{2} / \mathrm{WO}_{3}$ for ethylene dimerization. J. Catal. 1996, 160, 314-316. [CrossRef]

38. Sohn, J.R.; Kwon, S.H.; Shin, D.C. Spectroscopic studies on $\mathrm{NiO}$ supported on $\mathrm{ZrO}_{2}$ modified with $\mathrm{MoO}_{3}$ for ethylene dimerization. Appl. Catal. A Gen. 2007, 317, 216-225. [CrossRef]

39. Sohn, J.R.; Kim, H.W.; Park, M.Y.; Park, E.H.; Kim, J.T.; Park, S.E. Highly active catalyst of NiO-ZrO $\mathrm{Znodified}_{2}$ with $\mathrm{H}_{2} \mathrm{SO}_{4}$ for ethylene dimerization. Appl. Catal. A Gen. 1995, 128, 127-141. [CrossRef]

40. Sohn, J.R.; Kim, H.J. High catalytic activity of $\mathrm{NiO}-\mathrm{TiO}_{2} / \mathrm{SO}_{4}{ }^{2-}$ for ethylene dimerization. J. Catal. 1986, 101, 428-433. [CrossRef]

41. Al-Jarallah, A.M.; Anabtawi, J.A.; Siddiqui, M.A.B.; Aitani, A.M.; Al-Sa'doun, A.W. Part1 dimerization of ethylene to butane-1. Catal. Today 1992, 14, 1-121. [CrossRef]

42. Brogaard, R.Y.; Olsbye, U. Ethene oligomerization in Ni-containing zeolites: Theoretical discrimination of reaction mechanisms. ACS Catal. 2016, 6, 1205-1214. [CrossRef]

43. Yuen, S.; Kubsh, J.E.; Dumesic, J.A.; Topsoee, N.; Topsoee, H.; Chen, Y. Metal oxide-support interactions in silica-supported iron oxide catalysts probed by nitric oxide adsorption. J. Phys. Chem. 1982, 86, 3022-3032. [CrossRef]

44. Okamoto, Y.; Kubota, T.; Ohto, Y.; Nasu, S. Metal-oxide-support interactions in $\mathrm{Fe} / \mathrm{ZrO}_{2}$ catalysts. J. Phys. Chem. B 2000, 104, 8462-8470. [CrossRef]

45. Deo, G.; Wachs, I.E. Surface oxide-support interaction (SOSI) for surface redox sites. J. Catal. 1991, 129, 307-312. [CrossRef]

46. Xu, M.; He, S.; Chen, H.; Cui, G.; Zheng, L.; Wang, B.; Wei, M. TiO2-x-modified Ni nanocatalyst with tunable metal-support interaction for water-gas shift reaction. ACS Catal. 2017, 7, 7600-7609. [CrossRef]

47. Chen, P.; Khetan, A.; Yang, F.; Migunov, V.; Weide, P.; Stürmer, S.P.; Guo, P.; Kähler, K.; Xia, W.; Mayer, J.; et al. Experimental and theoretical understanding of nitrogen-doping-induced strong metal-support interactions in $\mathrm{Pd} / \mathrm{TiO}_{2}$ catalysts for nitrobenzene hydrogenation. ACS Catal. 2017, 7, 1197-1206. [CrossRef]

48. Wan, H.; Wu, B.; Xiang, H.; Li, Y. Fischer-Tropsch synthesis: Influence of support incorporation manner on metal dispersion, metal-support interaction, and activities of iron catalysts. ACS Catal. 2012, 2, 1877-1883. [CrossRef]

49. Kim, P.; Kim, Y.; Kim, H.; Song, I.K.; Yi, J. Synthesis and characterization of mesoporous alumina with nickel incorporated for use in the partial oxidation of methane into synthesis gas. Appl. Catal. A Gen. 2004, 272, 157-166. [CrossRef]

50. Delmon, B.; Delmon, B.; Thomas, J.M.; Bell, R.G.; Catlow, C.R.A.; Delmon, B.; Feijen, E.J.P.; Martens, J.A.; Jacobs, P.A.; Souverijns, W.; et al. Preparation of Solid Catalysts: Sections 2.2.2-2.3.3. In Handbook of Heterogeneous Catalysis; Wiley-VCH Verlag GmbH: Weinheim, Germany, 2008; pp. 264-365.

51. Rao, G.R.; Rao, C.N.R. A study of strong metal-support interaction based on an electron spectroscopic investigation of nitrogen adsorption on simulated nickel/titania, nickel/alumina and related catalyst surfaces. J. Phys. Chem. 1990, 94, 7986-7991. [CrossRef]

52. Tauster, S.J. Strong metal-support interactions. Acc. Chem. Res. 1987, 20, 389-394. [CrossRef]

53. Lee, M.; Yoon, J.W.; Kim, Y.; Yoon, J.S.; Chae, H.-J.; Han, Y.-H.; Hwang, D.W. Ni/SIRAL-30 as a heterogeneous catalyst for ethylene oligomerization. Appl. Catal. A Gen. 2018, 562, 87-93. [CrossRef]

54. Rynkowski, J.M.; Paryjczak, T.; Lenik, M. On the nature of oxidic nickel phases in $\mathrm{NiO} / \gamma-\mathrm{Al}_{2} \mathrm{O}_{3}$ catalysts. Appl. Catal. A Gen. 1993, 106, 73-82. [CrossRef]

55. Kim, P.; Kim, Y.; Kim, H.; Song, I.K.; Yi, J. Synthesis and characterization of mesoporous alumina for use as a catalyst support in the hydrodechlorination of 1,2-dichloropropane: Effect of preparation condition of mesoporous alumina. J. Mol. Catal. A Chem. 2004, 219, 87-95. [CrossRef] 
56. Boukha, Z.; Jiménez-González, C.; de Rivas, B.; González-Velasco, J.R.; Gutiérrez-Ortiz, J.I.; López-Fonseca, R. Synthesis, characterization and performance evaluation of spinel-derived $\mathrm{Ni} / \mathrm{Al}_{2} \mathrm{O}_{3}$ catalysts for various methane reforming reactions. Appl. Catal. B Environ. 2014, 158-159, 190-201. [CrossRef]

57. Kathiraser, Y.; Thitsartarn, W.; Sutthiumporn, K.; Kawi, S. Inverse $\mathrm{NiAl}_{2} \mathrm{O}_{4}$ on $\mathrm{LaAlO}_{3}-\mathrm{Al}_{2} \mathrm{O}_{3}$ : Unique catalytic structure for stable $\mathrm{CO}_{2}$ reforming of methane. J. Phys. Chem. C 2013, 117, 8120-8130. [CrossRef]

58. Heracleous, E.; Lee, A.F.; Wilson, K.; Lemonidou, A.A. Investigation of Ni-based alumina-supported catalysts for the oxidative dehydrogenation of ethane to ethylene: Structural characterization and reactivity studies. J. Catal. 2005, 231, 159-171. [CrossRef]

59. Mile, B.; Stirling, D.; Zammitt, M.A.; Lovell, A.; Webb, M. The location of nickel oxide and nickel in silica-supported catalysts: Two forms of " $\mathrm{NiO}^{\prime}$ and the assignment of temperature-programmed reduction profiles. J. Catal. 1988, 114, 217-229. [CrossRef]

60. Jiménez-González, C.; Boukha, Z.; de Rivas, B.; González-Velasco, J.R.; Gutiérrez-Ortiz, J.I.; López-Fonseca, R. Behavior of coprecipitated $\mathrm{NiAl}_{2} \mathrm{O}_{4} / \mathrm{Al}_{2} \mathrm{O}_{3}$ catalysts for low-temperature methane steam reforming. Energy Fuels 2014, 28, 7109-7121. [CrossRef]

61. Zhao, A.; Ying, W.; Zhang, H.; Ma, H.; Fang, D. Ni- $\mathrm{Al}_{2} \mathrm{O}_{3}$ catalysts prepared by solution combustion method for syngas methnation. Catal. Commun. 2012, 17, 34-38. [CrossRef]

62. Gayán, P.; Dueso, C.; Abad, A.; Adanez, J.; de Diego, L.F.; García-Labiano, F. NiO/ $\mathrm{Al}_{2} \mathrm{O}_{3}$ oxygen carriers for chemical-looping combustion prepared by impregnation and deposition-precipitation methods. Fuel 2009, 88, 1016-1023.

63. Zou, X.; Wang, X.; Li, L.; Shen, K.; Lu, X.; Ding, W. Development of highly effective supported nickel catalysts for pre-reforming of liquefied petroleum gas under low steam to carbon molar ratios. Int. J. Hydrogen Energy 2010, 35, 12191-12200. [CrossRef]

64. Wu, H.; Pantaleo, G.; La Parola, V.; Venezia, A.M.; Collard, X.; Aprile, C.; Liotta, L.F. Bi- and trimetallic Ni catalysts over $\mathrm{Al}_{2} \mathrm{O}_{3}$ and $\mathrm{Al}_{2} \mathrm{O}_{3}-\mathrm{MO}_{\mathrm{x}}(\mathrm{M}=\mathrm{Ce}$ or $\mathrm{Mg})$ oxides for methane dry reforming: $\mathrm{Au}$ and Pt additive effects. Appl. Catal. B Environ. 2014, 156-157, 350-361. [CrossRef]

65. Le Valant, A.; Bion, N.; Can, F.; Duprez, D.; Epron, F. Preparation and characterization of bimetallic $\mathrm{Rh}-\mathrm{Ni} / \mathrm{Y}_{2} \mathrm{O}_{3}-\mathrm{Al}_{2} \mathrm{O}_{3}$ for hydrogen production by raw bioethanol steam reforming: Influence of the addition of nickel on the catalyst performances and stability. Appl. Catal. B Environ. 2010, 97, 72-81. [CrossRef]

66. Diskin, A.M.; Cunningham, R.H.; Ormerod, R.M. The oxidative chemistry of methane over supported nickel catalysts. Catal. Today 1998, 46, 147-154. [CrossRef]

67. Al-Dalama, K.; Stanislaus, A. Temperature programmed reduction of $\mathrm{SiO}_{2}-\mathrm{Al}_{2} \mathrm{O}_{3}$ supported $\mathrm{Ni}$, $\mathrm{Mo}$ and NiMo catalysts prepared with EDTA. Thermochim. Acta 2011, 520, 67-74. [CrossRef]

68. Li, G.; Hu, L.; Hill, J.M. Comparison of reducibility and stability of alumina-supported Ni catalysts prepared by impregnation and co-precipitation. Appl. Catal. A Gen. 2006, 301, 16-24. [CrossRef]

69. Le Page, J.F.; Avnir, D.; Taglauer, E.; Guisnet, M.; Moretti, G.; Che, M.; Bozon-Verduraz, F.; Anpo, M.; Roduner, E.; Knözinger, H. Characterization of Solid Catalysts: Sections 3.1.4-3.2.2. In Handbook of Heterogeneous Catalysis; Wiley-VCH Verlag GmbH: Weinheim, Germany, 2008; pp. 582-689.

70. Singh, K.S.W.; Rouquerol, J.; Bergeret, G.; Gallezot, P.; Vaarkamp, M.; Koningsberger, D.C.; Datye, A.K.; Niemantsverdriet, J.W.; Butz, T.; Engelhardt, G.; et al. Characterization of Solid Catalysts: Sections 3.1.1-3.1.3. In Handbook of Heterogeneous Catalysis; Wiley-VCH Verlag GmbH: Weinheim, Germany, 2008; pp. 427-582.

71. Metzger, E.D.; Brozek, C.K.; Comito, R.J.; Dincă, M. Selective dimerization of ethylene to 1-butene with a porous catalyst. ACS Cent. Sci. 2016, 2, 148-153. [CrossRef]

72. Yoon, J.S.; Lee, Y.; Ryu, J.; Kim, Y.-A.; Park, E.D.; Choi, J.-W.; Ha, J.-M.; Suh, D.J.; Lee, H. Production of high carbon number hydrocarbon fuels from a lignin-derived $\alpha-\mathrm{O}-4$ phenolic dimer, benzyl phenyl ether, via isomerization of ether to alcohols on high-surface-area silica-alumina aerogel catalysts. Appl. Catal. B Environ. 2013, 142-143, 668-676. [CrossRef]

73. Emeis, C.A. Determination of integrated molar extinction coefficients for infrared absorption bands of pyridine adsorbed on solid acid catalysts. J. Catal. 1993, 141, 347-354. [CrossRef]

(C) 2019 by the authors. Licensee MDPI, Basel, Switzerland. This article is an open access article distributed under the terms and conditions of the Creative Commons Attribution (CC BY) license (http://creativecommons.org/licenses/by/4.0/). 